\title{
$\dot{\nabla}_{\text {Nursing }}^{\text {Global Academic }}$
}

\section{Aloenxertia e xenoenxertia de tilápia no tratamento de queimaduras pediátricas de $2^{\circ}$ grau}

\author{
Tilapia allograft and tilapia xenograft in the treatment of pediatric 2nd degree burns
}

Aloinjerto de tilapia y xenoinjerto de tilapia en el tratamiento de quemaduras pediátricas de $2^{\circ}$ grado

\author{
Ana Beatriz Rebouças de \\ Azevedo Marques ${ }^{1}$ \\ ORCID: 0000-0001-6977-319X \\ Camila Bouçós Justo ${ }^{1}$ \\ ORCID: 0000-0003-2144-7218 \\ Graziella Souza Guimarães ${ }^{1}$ \\ ORCID: 0000-0001-5430-6898 \\ ${ }^{1}$ Universidade Santo Amaro. São \\ Paulo, Brasil.
}

\section{Como citar este artigo:}

Marques ABRA, Justo CB, Guimarães GS. Aloenxertia e xenoenxertia de tilápia no tratamento de queimaduras pediátricas de $2 \circ$ grau. Glob Acad Nurs. 2021;2(3):e158. https://dx.doi.org/10.5935/26755602.20200158

\section{Autor correspondente:}

Ana Beatriz Rebouças de Azevedo Marques

E-mail: ana-beatriz99@hotmail.com

Editor Chefe: Caroliny dos Santos Guimarães da Fonseca Editor Executivo: Kátia dos Santos Armada de Oliveira

Submissão: 29-03-2021

Aprovação: 08-04-2021

\section{Resumo}

Objetivou-se estudar o uso da aloenxertia e xenoenxertia de tilápia nas queimaduras pediátricas de 2o grau quanto às terapêuticas e resultados clínico-cirúrgicos. Trata-se de uma revisão narrativa de literatura realizada através de levantamento de artigos nas bases de dados MEDLINE via PubMed, Cochrane Library, VIA ELSEVIER, BVS, LILACS, Scopus. A aloenxertia é indicada para a cobertura de lesões de espessura total, cicatrização de feridas de espessura parcial, assim como a preparação do leito para uma posterior autoenxertia. Essa opção, entretanto, torna-se limitada pelos insuficientes bancos de pele no Brasil. $O$ xenoenxerto pode ser considerado uma solução no âmbito terapêutico e socioeconômico. O uso da pele da tilápia do Nilo apresenta benefícios no tratamento de queimaduras e, no Brasil, a grande produção desse peixe viabiliza o acesso à sua pele devido ao descarte deste subproduto. Seu uso representa o progresso do manejo clínico e cirúrgico ao analisar seus benefícios, possíveis complicações e impactos socioeconômicos, além da necessidade de explorar novos métodos terapêuticos para o melhor tratamento a partir de recursos disponíveis.

Descritores: Queimaduras; Pediatria; Aloenxertos; Xenoenxertos; Tilápia do Nilo.

\section{Abstract}

The aim of this study was to study the use of tilapia allograft and tilapia xenograft in pediatric second-degree burns in terms of therapeutics and clinical-surgical results. This is a narrative literature review carried out through a survey of articles in the MEDLINE databases via PubMed, Cochrane Library, VIA ELSEVIER, BVS, LILACS, Scopus. Allograft is indicated for covering full-thickness wounds, healing partial-thickness wounds, as well as preparing the bed for subsequent self-grafting. This option, however, becomes limited by the insufficient skin banks in Brazil. Xenograft can be considered a therapeutic and socioeconomic solution. The use of Nile tilapia skin has benefits in the treatment of burns, and, in Brazil, the large production of this fish allows access to its skin due to the disposal of this by-product. Its use represents the progress of clinical and surgical management by analyzing its benefits, possible complications, and socioeconomic impacts, in addition to the need to explore new therapeutic methods for the best treatment based on available resources.

Descriptors: Burns; Pediatrics; Allografts; Heterografts; Cichlids.

\section{Resumén}

El objetivo de este estudio fue estudiar el uso de aloinjerto de tilapia y xenoinjerto de tilapia en quemaduras de segundo grado pediátricas en términos de terapéutica y resultados clínico-quirúrgicos. Se trata de una revisión de la literatura narrativa realizada a través de una encuesta de artículos en las bases de datos de MEDLINE a través de PubMed, Cochrane Library, VIA ELSEVIER, BVS, LILACS, Scopus. El aloinjerto está indicado para cubrir lesiones de espesor total, cicatrizar heridas de espesor parcial, así como preparar el lecho para el posterior autoinjerto. Esta opción, sin embargo, se ve limitada por la insuficiencia de los bancos de piel en Brasil. El xenoinjerto puede considerarse una solución terapéutica y socioeconómica. El uso de piel de tilapia del Nilo tiene beneficios en el tratamiento de quemaduras y, en Brasil, la gran producción de este pescado permite el acceso a su piel debido a la eliminación de este subproducto. Su uso representa el avance del manejo clínico y quirúrgico al analizar sus beneficios, posibles complicaciones e impactos socioeconómicos, además de la necesidad de explorar nuevos métodos terapéuticos para el mejor tratamiento en base a los recursos disponibles.

Descriptores: Quemaduras; Pediatría; Aloenjertos; Xenoinjertos; Cíclidos. 


\section{Introdução}

As queimaduras são definidas como lesões traumáticas sobre o revestimento do corpo, desde a epiderme até tecidos mais profundos. Podem ser causadas por contato com substâncias químicas, radiação, chama direta, energia elétrica, agentes térmicos e inflamáveis. A gravidade do dano está associada tanto ao fator causal quanto a profundidade da queimadura, o tempo e área de exposição. Esse tipo de lesão retrata um cenário grave para a saúde pública, principalmente por ser a segunda causa de acidentes mais frequentes no período da infância, assim como apresenta o maior índice de morbimortalidade nos acidentes por trauma. As crianças encontram-se numa situação de maior vulnerabilidade ao óbito em relação aos adultos, por conta dos sistemas musculoesquelético e imunológico ainda imaturos. Da mesma maneira, devido a pele mais sensível, suas queimaduras podem evoluir para níveis mais profundos com consequente queda do estado geral $^{1-4}$.

Com o início da pandemia da COVID-19 no início de 2020 no Brasil, junto à necessidade de a população adequarse à nova realidade de distanciamento social, hábitos de higiene e consequentemente um maior período das crianças dentro de casa, a Sociedade Brasileira de Pediatria publicou uma nota de alerta a qual evidenciou um aumento na incidência de queimaduras em crianças durante a quarentena, principalmente relacionada ao uso de álcool em gel. Foi demonstrado que as queimaduras pediátricas cresceram em $25 \%$ desde o início da pandemia ${ }^{5,6}$.

A maior parte dos casos ocorre em crianças menores de 5 anos de idade, faixa etária na qual o desenvolvimento neuropsicomotor não está completo, o que somado a fatores socioeconômicos e falha na vigilância pelos pais ou responsáveis, propicia a ocorrência das queimaduras $^{2}$. Estudos apontam o sexo masculino como o mais acometido e situações envolvendo líquidos quentes como predominantes em todas as fases pediátricas. Lesões inalatórias também podem ocorrer, como nos incêndios em lugares fechados e queimaduras próximas ao rosto, o que eleva a taxa de mortalidade, e tem como principal causa a intoxicação por monóxido de carbono ${ }^{7}$. Em relação a localização das lesões, no Brasil foi indicada uma prevalência na região do tronco ${ }^{3}$.

As queimaduras de segundo grau são subdivididas em espessura parcial superficial, que é caracterizada por atingir a epiderme e a porção papilar da derme, manifestar formação de bolhas devido ao desprendimento da camada epidérmica e ao exsudato dos capilares remanescentes da camada profunda da derme, bem como hiperemia intensa, edema, dor e sensibilidade, indicando que os anexos cutâneos não foram atingidos, os quais serão responsáveis pela regeneração espontânea em até 21 dias; e espessura parcial profunda, que afeta a epiderme e tanto a derme papilar quanto a reticular, desse modo, em consequência da grande destruição do plexo vascular, a hiperemia e o exsudato são menores, porém ainda é possível o aparecimento de bolhas. A partir dos escassos anexos dérmicos restantes, pode ocorrer a regeneração, entretanto será acompanhada de cicatriz. Pelo mesmo motivo, essa lesão é menos dolorosa que a superficial e tem maior possibilidade de infecção e evolução para espessura total ${ }^{7,8}$.

A superfície corporal queimada (SCQ) pode ser calculada de acordo com a "Regra dos Noves", a qual divide o corpo em segmentos que são multiplicados pelo número nove. No entanto, para as crianças, o uso do diagrama de Lund-Browder é a escolha para um cálculo com maior acurácia, em razão das diferentes proporções em que o corpo é subdividido ${ }^{9,10}$. As indicações para hospitalização das crianças levam em conta esse cálculo e a profundidade das lesões, como nas queimaduras de 2 o grau acometendo mais de $10 \%$ da superfície corpórea, de $3 \%$ grau acometendo mais de $5 \%$, e de 2ㅇ ou 3으 graus em face, órgãos genitais e períneo. Além de queimaduras químicas, elétricas e associadas a trauma concomitante, vitimização infantil ou falta de condições para manejo domiciliar, doenças crônicas de base ou lactentes jovens, lesão inalatória e queimaduras circunferenciais ${ }^{7}$.

Esse trauma provoca uma resposta local, metabólica e sistêmica, com perda da homeostasia dos líquidos corporais. De imediato, mediadores vasoativos são liberados e promovem o aumento da permeabilidade vascular, com deslocamento de fluidos do meio intravascular para o interstício, o que resulta em hipovolemia e edema na região queimada. 0 edema costuma progredir até 24 horas, momento em que se inicia a reparação do endotélio vascular, e em grandes queimaduras pode originar-se em tecidos não queimados devido a exacerbada hipoproteinemia ${ }^{7,11,12}$.

Na regulação da temperatura, é necessário atentarse às crianças, que são mais propensas a hipotermia ${ }^{7}$. Há também maior concentração dos hormônios contrarreguladores, o que faz com que seja de suma importância o suporte de nutrição enteral precoce, evidenciado em estudo que pode propiciar menor tempo de internação hospitalar, diminuir a ocorrência de translocação bacteriana e a possibilidade de complicações infecciosas, tendo em vista que o grande índice de mortalidade infantil nas queimaduras deve-se a infecção, síndrome da resposta inflamatória sistêmica e sepse $\mathrm{e}^{1,3,9,11}$.

No manejo do paciente queimado é fundamental restabelecer a permeabilidade de vias aéreas, ventilação, circulação, ressuscitação hídrica, débito urinário e analgesia, de acordo com o protocolo do trauma para a abordagem de queimados, a terapêutica prossegue com a atenção voltada à ferida, e se estende para a fase de restituição e abordagem cicatricial $^{2,7,12}$. O tratamento adequado a ser aplicado é uma das mais importantes vertentes, em razão da alta morbidade e mortalidade provocadas por este trauma ${ }^{9}$. A primeira etapa consiste na irrigação da lesão, na qual qualquer coágulo presente na ferida é desarranjado, possibilitando o início de um sangramento. A hemostasia pode ser feita por meio de pressão direta ou através do reparo vascular se for preciso abordagem cirúrgica ${ }^{10}$.

O desbridamento da ferida é necessário quando há desvitalização, para a retirada do tecido necrótico e minimização de infecções bacterianas. Dependendo da urgência e estabilidade do paciente, esse processo pode ocorrer à beira do leito, no entanto o desbridamento 
cirúrgico convencional é o padrão ouro. A forma de excisão total remove todo o tecido necrótico, mas pode resultar em deformidades, já na excisão tangencial a remoção é feita em camadas até encontrar tecido vitalizado. Esta técnica apresenta melhores resultados estéticos e para futuras reconstruções, porém possibilita o risco de sangramento, remoção desigual de profundidade e incompleta do tecido desvitalizado ${ }^{10}$. O desbridamento das queimaduras de 2 o grau profundo e 30 grau é essencial, e normalmente em seguida necessitam de enxertia ${ }^{13}$. Esse processo muitas vezes apresenta diversos desafios para a Medicina, desde a sua disponibilidade até suas etapas de aplicação.

O aloenxerto e o xenoenxerto com pele de tilápia são duas opções que devem ser cada vez mais exploradas. Desse modo, o estudo visa analisar o uso da aloenxertia e xenoenxertia de tilápia nas queimaduras pediátricas de 20 grau quanto à terapêutica e resultados clínico-cirúrgicos, destacando os benefícios de seu uso para a melhoria do manejo das queimaduras a partir de recursos disponíveis, suas complicações e a relação custo-benefício, o que é de extrema importância para o enriquecimento literário nos departamentos de Pediatria e Cirurgia Plástica.

\section{Metodologia}

Revisão narrativa de literatura a partir de busca no MEDLINE via PubMed, Cochrane Library - Cochrane Central Register of Controlled Trial (CENTRAL), em base VIA ELSEVIER, BVS, LILACS, Scopus, utilizando palavras-chave e sinônimos sobre a aloenxertia e xenoenxertia de tilápia em crianças com queimaduras de 20 grau, com objetivo de adaptar os requisitos da pesquisa a cada banco de dados. Por fim, foi utilizada a técnica Snowballing para ampliar a busca a partir das referências dos estudos incluídos.

Com o intuito de encontrar artigos relevantes para essa revisão, foram selecionados majoritariamente aqueles publicados entre 2016 e 2020, com exceção daqueles que incluem conceitos ainda atualizados, e utilizados descritores disponíveis na plataforma Descritores em Ciências da Saúde (DeCS): Queimaduras; Pediatria; Aloenxertos; Xenoenxertos; Tilápia do Nilo. Foram consideradas quaisquer publicações sobre aloenxertia e xenoenxertia de tilápia em crianças que apresentaram queimaduras de $2 \stackrel{\circ}{\circ}$ grau, exceto protocolos, e qualquer desfecho que tenha sido avaliado e reportado pelos autores das publicações. Também se incluiu na seleção todos os pacientes pediátricos, independente de sexo, que apresentaram queimaduras de 2 o grau. Não houve restrições em relação ao fator causal das queimaduras.

\section{Resultados e Discussão}

Os enxertos são fragmentos de pele retirados de uma área doadora e deslocados para a área receptora, que fornecerá o suprimento sanguíneo. Existem diversos tipos de enxerto em relação a sua espessura, como enxerto de pele total, parcial e compostos; e em relação a sua origem como o autoenxerto, proveniente do próprio paciente, o isoenxerto, de um gêmeo univitelino para o outro, o aloenxerto, entre indivíduos da mesma espécie, e o xenoenxerto, entre espécies diferentes. Uma outra forma de preencher a ferida é através de retalhos, que diferentemente dos enxertos, possuem vascularização própria por meio de vasos de um pedículo que exerce a comunicação entre o retalho e o leito receptor. Para ser realizado deve haver sobras de pele e mobilidade na região doadora, de forma que o pedículo não seja tracionado com o posicionamento do retalho ${ }^{14}$.

O aloenxerto pode ser usado em crianças com uma grande superfície corporal queimada, quando não é possível a enxertia autóloga, e com a finalidade de amenizar a dor, reduzir o risco de infecções e contribuir na reepitelização. As queimaduras de segundo grau, muitas vezes necessitam de trocas de curativos constantes, causando o aprofundamento da lesão e propiciando a infecção da ferida e dor, o que evidencia os possíveis benefícios da utilização dessa técnica. Os aloenxertos favorecem a cicatrização da ferida, diminuem a perda de fluidos corporais e promovem uma cobertura precoce e temporária. A rejeição ocorre depois de alguns dias ou semanas pelas diferenças genéticas entre doador e receptor, por este motivo quando possível, dá-se preferência ao enxerto de um parente de primeiro grau para que a rejeição possa ser postergada ${ }^{12,15}$.

A aloenxertia é indicada para a cobertura de lesões de espessura total, cicatrização de feridas de espessura parcial, assim como a preparação do leito para uma posterior autoenxertia. Para alguns pacientes pediátricos ainda se apresenta como uma melhor alternativa à autoenxertia, por não causar maiores complicações clínicas de descompensação homeostática, resultante de uma nova lesão proveniente da coleta do autoenxerto, principalmente na fase aguda da queimadura na qual as crianças estão suscetíveis a perdas eletrolíticas e choque. Nesses casos, a aloenxertia possibilita a excisão precoce do ferimento ${ }^{15}$.

Estudo realizado no Instituto Jawaharlal de Educação e Pesquisa Médica em Pós-Graduação demonstrou que o aloenxerto, quando comparado aos substitutivos dérmicos sintéticos, apresenta mais vantagens e menos desvantagens. Entre as opções de substitutivos dérmicos sintéticos, o colágeno é o que costuma ter maior disponibilidade e apresenta propriedades similares às do aloenxerto, porém seu custo é mais elevado e sua absorção ocorre entre 3 e 6 dias, o que faz com que seja necessário maior número de trocas. $O$ aloenxerto permanece na ferida de 2 a 3 semanas, desse modo é considerado mais eficaz na redução da dor e no controle de infecções ${ }^{15}$.

A opção da aloenxertia, entretanto, torna-se limitada pela insuficiente quantidade de bancos de pele no Brasil. Nesse cenário, o xenoenxerto pode ser considerado uma solução tanto do ponto de vista terapêutico quanto socioeconômico. O uso da pele da tilápia do Nilo (Oreochromis niloticus) tem sido cada vez mais estudado, e apresenta diversos benefícios no tratamento de queimaduras. No Brasil, a grande produção desse peixe viabiliza o acesso à sua pele devido ao descarte deste subproduto. Estudos histológicos demonstraram eficácia na aderência de lesões, capacidade de reter umidade, alta resistência e extensão quando submetidas a tração, e estrutura morfológica semelhante às humanas, o que limita as respostas imunes em relação a ela ${ }^{16,19}$. 
O xenoenxerto de tilápia possui uma alta concentração de colágeno tipo I e atividade antimicrobiana, anti-inflamatória, antioxidante, anti-hipertensiva, nervo protetora, e de estímulo para o tecido de granulação devido ao seu diversificado conteúdo de aminoácidos. A partir dessas propriedades peptídicas, tem a capacidade de expressar os fatores de crescimento epitelial e de fibroblastos, que induzem a diferenciação, reepitelização e proliferação celular, de acordo com suas características hidrofílicas. Os componentes de sua colônia indicam uma microbiota normal e não infecciosa, e ainda passa por etapas químicas de preparação da pele, limpeza, descontaminação, desidratação e radioesterilização, antes de ser usada como enxerto ${ }^{18,20,21}$

Pesquisas realizadas no Instituto Dr. José Frota (IJF), hospital público de Fortaleza, na etapa 2 do ensaio clínico sobre o uso de tilápias na enxertia de queimaduras de segundo grau superficiais e profundas, apontou resultados como ótima adesão à ferida, que serviu como fator de proteção a infecções e perda de líquidos, diminuição da dor e dos custos. Foi observada também a permanência do enxerto até a cicatrização nas lesões de segundo grau superficiais, não sendo necessária a sua troca, o que também foi demonstrado em relato de caso descrito em Fortaleza, e usado como comparativo em estudo realizado no Hospital São Marcos em Pernambuco, com o uso de hidrofibra com prata Aquacel $\mathrm{Ag}^{\circledR}$ em queimaduras de segundo grau superficiais e profundas, no qual o uso do xenoenxerto da tilápia demonstrou a menor ocorrência de substituição de curativos $^{16,19,20}$.

Edmar Maciel Lima et al. demonstra o uso de pele de Tilápia como xenoenxerto no relato de caso de uma paciente com queimaduras de segundo grau profundo envolvendo principalmente as regiões inguinal e genital após lesão térmica por chamas de fogo. A paciente apresentou $13,5 \%$ da superfície corporal queimada. Com o uso da tilápia foi necessário o período de 16 dias para a reepitelização das queimaduras, enquanto se tivesse sido empregado tratamento convencional, seria necessário em torno de 3 semanas para a total cicatrização. Além disso, o uso deste xenoenxerto mostrou resultados como a ausência de efeitos colaterais, antigenicidade e toxicidade além de benefícios como a flexibilidade, aderência, conservação da umidade, fator de diminuição de entrada de microrganismos e diminuição de troca de curativos. Ademais, pôde-se observar bons resultados com a pele de tilápia, inclusive em regiões do corpo pouco exploradas a partir deste tratamento como a região genital e inguinal, mesmo com a necessidade de reposição de pele como no relato de caso $^{22}$.

\section{Conclusão}

O estudo da aloenxertia e xenoenxertia através da pele de tilápia, nas queimaduras pediátricas, retrata o progresso do manejo clínico e cirúrgico ao comparar os seus benefícios, possíveis complicações e impactos socioeconômicos, e o enriquecimento da pesquisa literária acerca do assunto. Tendo em vista que o número de estudos ainda é escasso, essa pesquisa representa uma base necessária para futuros trabalhos. O uso da tilápia constitui uma alternativa para a demanda dos bancos de pele não atendida e demonstra boa aderência no leito da ferida, menor necessidade de troca de curativos, e maior potencial de disponibilidade, quando comparado ao aloenxerto, e reflete a necessidade de explorar novos métodos terapêuticos para o tratamento ideal do paciente a partir de recursos disponíveis, eficazes e com melhor custo-benefício.

\section{Referências}

1. Valentini M, Seganfredo FB, Fernandes SA. Pediatric enteral nutrition therapy for burn victims: when should it be initiated? Rev. Bras. ter. int. 31(3): 393-402 [internet] 2019; [acesso em 29 de maio de 2020]. Disponível em:

https://www.ncbi.nlm.nih.gov/pmc/articles/PMC7005954/

2. Guimarães RW, Porciuncula MB, Avila JEHG, Dias MFG, Adorno J, Suassuna SMSS, et al. Tratamento pediátrico de grande queimado agudo: Manejo clínico, cirúrgico e uso de matriz de regeneração dérmica. Revista Brasileira de Queimaduras [internet]. 2019 [acesso em 29 de maio de 2020]; 18(1). Disponível em: http://rbqueimaduras.org.br/details/462

3. Nigro MVAS, Maschietto SM, Damin R, Costa CS, Lobo GRA. Perfil epidemiológico de crianças de 0-18 anos vítimas de queimaduras atendidas no Serviço de Cirurgia Plástica e Queimados de um Hospital Universitário no Sul do Brasil. Rev. Bras. Cir Plást. [internet] 2019 [acesso em 29 de maio de 2020];34(4). Disponível em: http://www.rbcp.org.br/details/2667/pt-BR/perfil-epidemiologico-de-criancas-de0-18-anos-vitimas-de-queimaduras-atendidas-no-servico-de-cirurgia-plastica-e-queimados-de-um-hospital-universitar

4. Salvatierra VD. Intervenciones de Enfermería en la atención inicial del paciente pediátrico quemado. Visión enfermaría actualizada, 13(47): 29-37 [internet] setembro de 2016; [acesso em 29 de maio de 2020]. Disponível em: https://pesquisa.bvsalud.org/portal/resource/pt/biblio-1008585

5. Sociedade Brasileira de Pediatria [Homepage na internet]. Prevenção de Queimaduras em tempos de COVID-19 [acesso em 22 de março de 2021]. Disponível em: https://www.sbp.com.br/fileadmin/user_upload/22630b-NA_-_Prevencao_Queimaduras_tempos_Covid19.pdf

6. Ribeiro AP, Santos EM, Brunello MEF, Wysocki AD. COVID-19: repercussões e orientações acerca dos profissionais de enfermagem. Glob Acad Nurs [internet] 2021; 1(3):e61 [acesso em 05 de abril de 2021]. Disponível em: https://globalacademicnursing.com/index.php/globacadnurs/article/view/102/112

7. Guimarães FMF, Abramovici S. Tratado de Pediatria. 4. ed. Barueri: Editora Manole Ltda; 2017.

8. Universidade Federal de Santa Catarina, Programa de Valorização do Profissional da Atenção Básica. Módulo Eventos Agudos em Situações Clínicas - Queimaduras [internet] 2014; [acesso em 30 de maio de 2020]. Disponível em:

https://ares.unasus.gov.br/acervo/html/ARES/13962/1/QueimadurasPROVAB.pdf 
9. Avci V, Kocak OF. Treatment algorithm in 960 pediatric burn cases: A review of etiology and epidemiology. Pakistan Journal of Medical Sciences, 34(5): 1185-1190 [internet] 2018; [acesso em 30 de maio de 2020]. Disponível em:

https://www.ncbi.nlm.nih.gov/pmc/articles/PMC6191793/

10. Block L, King TW, Gosain A. Debridement Techniques in Pediatric Trauma and Burn-Related Wounds. Advances in Wound Care, 4(10): 596606 [internet] 1 de outubro de 2015; [acesso em 30 de maio de 2020]. Disponível em:

https://www.ncbi.nlm.nih.gov/pmc/articles/PMC4593934/

11. Nanbu DY, Rodrigues KR, Forte RSG, Ferreira AVS. Pronto-socorro, 3ed (Coleção pediatria do Instituto da Criança do HCFMUSP; 7). Barueri: Editora Manole Ltda; 2018. P.283-91.

12. Jaeger MRO, Ferreira LM, Falcão T, Ely PB, Chem E. Alotransplante de pele como alternativa para o tratamento da queimadura dolorosa da criança [internet] 2015 [acesso em 30 de maio de 2020];14(1). Disponível em: http://rbqueimaduras.org.br/details/244/ptBR/alotransplante-de-pele-como-alternativa-para-o-tratamento-da-queimadura-dolorosa-da-crianca

13. Kokiso D, Santos NSV, Arruda PDM, Gomide NFM, Stanzani FR, Vidal MA. Avaliação das variáveis associadas à demora na enxertia do queimado agudo. Revista Brasileira de Queimaduras [internet] 2014 [acesso em 2 de junho de 2020];13(4). Disponível em: http://www.rbqueimaduras.com.br/details/223/pt-BR/avaliacao-das-variaveis-associadas-a-demora-na-enxertia-do-queimado-agudo

14. Sociedade Brasileira de Cirurgia Dermatológica. [Homepage na internet]. Enxertos e Retalhos [acesso em 2 de junho de 2020]. Disponível em: https://www.sbcd.org.br/procedimentos/cirurgicos/enxertos-e-retalhos/

15. Gupta S, Mohapatra DP, Chittoria RK, Subbarayan E, Reddy SK, Chavan V, et al. Human skin allograft: Is it a viable option in management of burn patients? Journal of Cutaneous and Aesthetic Surgery, [internet] 2019 [acesso em 2 de junho de 2020];12(2):132-135. Disponível em: http://www.jcasonline.com/article.asp?issn=0974-2077;year=2019; volume=12;issue=2; spage=132; epage=135; aulast=Gupta

16. Júnior EML. Tecnologias inovadoras: uso da pele da tilápia do Nilo no tratamento de queimaduras e feridas. Revista Brasileira de Queimaduras [internet]. 2016 [acesso em 2 de junho de 2020]16(1). Disponível em: http://www.rbqueimaduras.com.br/details/339/pt$\mathrm{BR} /$ tecnologias-inovadoras--uso-da-pele-da-tilapia-do-nilo-no-tratamento-de-queimaduras-e-feridas

17. Ciornei B, David VL, Boia ES. Future prospects in the treatment of pediatric burns. A review of the Nile tilapia derived biological options for treating superficial partial thickness burns. Jurnalul Pediatrului [internet]. 2019 [acesso em 2 de junho de 2020];22. Disponível em: http://www.jurnalulpediatrului.ro/archive/87-88/87-88-03.pdf

18. Moghaddam-Jafari S, Ziaei-Darounkalaei N, Severi F, Moghaddam-Jafari S. Fish Skin as an Alternative Biological Wound Dressing in the Wound Healing Process. EC Veterinary Science [internet]. 2020 [acesso em 2 de junho de 2020];5(3). Disponível em: https://www.ecronicon.com/ecve/ECVE-05-00209.php

19. Miranda MJB, Brandt CT. Xenoenxerto (pele da Tilápia-do-Nilo) e hidrofibra com prata no tratamento das queimaduras de II grau em adultos. Rev. Bras. Cir. Plást. [internet]. 2018 [acesso em 10 de junho de 2020];34(1). Disponível em: http://rbcp.org.br/details/2349/ptBR/xenoenxerto--pele-da-tilapia-do-nilo--e-hidrofibra-com-prata-no-tratamento-das-queimaduras-de-ii-grau-em-adultos

20. Lima-Junior EM, de Moraes Filho MO, Costa BA, Fechine FV, de Moraes MEA, Silva-Junior FR, et al. Innovative treatment using tilapia skin as a xenograft for partial thickness burns after a gunpowder explosion. Journal of surgical case reports. [Internet]. 2019 [acesso em 10 de junho de 2020];6:181. Disponível em: https://www.ncbi.nlm.nih.gov/pmc/articles/PMC6565829/

21. Jones F. In the skin of tilapia. Revista Pesquisa FAPESP [internet]. 2019 [acesso em 10 de junho de 2020];280. Disponível em: https://revistapesquisa.fapesp.br/en/in-the-skin-of-tilapia/

22. Lima Júnior EM, Moraes Filho MO, Costa BA, Uchôa AMN, Martins CB, Moraes MEA, et. al. Tratamento de queimaduras de segundo grau profundo em abdômen, coxas e genitália: uso da pele de tilápia como um xenoenxerto. Rev. Bras. Cir. Plást. 35(2): 243-248 [internet] 2020; [acesso em 22 de março de 2021]. Disponível em: http://www.rbcp.org.br/details/2755/pt-BR/tratamento-de-queimaduras-desegundo-grau-profundo-em-abdomen--coxas-e-genitalia--uso-da-pele-de-tilapia-como-um-xenoenxerto 